\title{
Ethnographic Tales from the School Restaurant
}

\section{Gurpinder Singh Lalli}

University of Wolverhampton, UK. Email: gurpinder.lalli@wlv.ac.uk

\section{Discipline}

Education [D2]

\section{Subdiscipline}

Sociology

\section{Academic Level}

Postgraduate

\section{Contributor Biography}

Gurpinder Singh Lalli currently holds a Lectureship at the University of Wolverhampton, teaching Education, Childhood and Family Studies within the Institute of Education. Prior to this, he gained Qualified Teaching Status whilst teaching in Further Education Colleges. Gurpinder is currently a member of the Higher Education Academy (HEA) and holds the status of a Fellow. His first degree was gained at Coventry in sociology and social policy with an MA focused on social and cultural theory, gained at Staffordshire University. For his $\mathrm{PhD}$, Gurpinder carried out an ethnographic case study on the impact of food on learning at the University of Leicester. Research interest areas include sociology of education, culture and identity, pedagogic practices, learning spaces and school meals.

\section{Published Articles}

Lalli, G. (2017) School Meals: A Learning Environment? Ph.D. Thesis. University of Leicester: U.K. (In progress) 


\begin{abstract}
This case study is aimed at postgraduate and early career researchers who wish to embark on using ethnographic techniques in educational research. The topic in question is school food and its impact upon learning. In this case, it is the social aspect which is being addressed. This research did not aim to address the nutritious element but the way pupils ate in what is termed the 'school restaurant'. There is a particular focus on observation as this was used as one of the key methods for collecting data. The reason for presenting an account of observational ethnographic research stems from the complexities involved in using this method. This case study presents a view on the difficulties encountered in observational research and for that reason, it is particularly useful to draw upon reflections from the study. The case study also introduces ethnography, interpretivism and social constructivism as key concepts. Overall, the school restaurant was highlighted as a learning space and an opportunity for pupils to sit and eat together whilst interacting with fellow peers. This particular resource allows new and emerging students to question and think about ethnography in education.
\end{abstract}

\title{
Learning Outcomes
}

By the end of the case, students should

- Understand the complexity between the insider and outsider debate in ethnography

- Recognise the complex nature of observation as a research tool

- Recognise the relationship between the research idea and research proposal

- Recognise key methodological concepts.

- Understand the importance of validity and reliability in ethnographic research

- Understand the nature of ethnographic research in this context

- Recognise the reflective process and re-writing of research questions

- Understand the importance of piloting 


\section{Case Study}

\section{Project Overview and Context: Ethnographic Tales from the School Restaurant}

I embarked on this study in January 2012 at a time which saw the state holding a firm grip on Free School Meals (FSM) in the UK. Although, there were already ample studies which had investigated the nutritional aspect of school food, there was a gap in literature surrounding the school meal as a social learning space. The study was co-funded by University and Leicester and Peartree Academy. The acronym Peartree Academy has been used in order to disguise the identity of the school. I was tasked with developing a research proposal based on an idea that was provided by my first supervisor.

Peartree Academy is based in the UK and gained academy status in 2007, following what was originally a 'failing' school. The social demographics upon which the school is situated means that uptake in Free School Meals (FSM) is above average. It is also important to highlight that the school is set in a socially deprived area, with high levels of unemployment. This particular case study details the overall nature of the study with a key focus on methodology and more specifically observational research. It merely seeks to help the prospective student and reader to establish recognition for some of the expectations required in terms of carrying out a research. I did not foresee that I would face difficulties in starting, accessing and collecting data. The key piece of advice for any early career researcher conducting ethnography would be to set realistic expectations of what is able to be achieved, particularly paying attention to life events and future career prospects. For me, I had already established my career path at this stage and already started to plan a family. Another key point I would like to make at this stage is that a full-time studentship is not comparable to a full-time occupation. A PhD study of this kind places a hold on the mind of the ethnographer, one which lasts longer the 9am to 5pm working day. This ethnographic $\mathrm{PhD}$ study started on $10^{\text {th }}$ October 2011, when the studentship was first advertised and preparations for the interview were underway. The first article for the literature review came from a newspaper article, which I obtained whilst flying above the North Atlantic Ocean, on a family vacation. The 'write-up' is not a process that takes place during the final year of a $\mathrm{PhD}$ thesis; it begins as soon as the study commences, from the research proposal to taking the first step into the school. 


\section{Research Methodology and Ethnography}

This section details some key concepts including ethnography, social constructivism and interpretivism. Ethnographic techniques were adopted in order to capture the impact of food upon learning in the school restaurant at Peartree Academy. This method was influenced by a number of previous ethnographies (Pike, 2010; Acker, 1999; Burgess, 1983; Ball, 1981) which helped to make the decision. This was written as a case study and a social constructivist position was employed, taking an interpretivist approach in order to extrapolate meaning making from respondents in the study. Writing the ethnography started in January 2012 as I made my first journal entry following a supervision with my supervisor. Ethnography relies on developing a full description of the school and everyday lives of the people within it (Hammersley and Atkinson, 2007). As a method, ethnography refers to the way of studying, knowing and reporting about the world (Atkinson, 2007). Moreover, ethnography is also a frame of mind and helps the research to remain open to everything unknown; a suspension of disbelief (Atkinson et al, 2007: 160). For Vygotsky (1978) constructivism is known as social constructivism because it explores culture and social context. Vygotsky believes learning and development is a collaborative activity and that children develop cognitive functioning in the context of socialisation and education (Vygotsky, 1978). In order to better understand the paradigm of the research here, it is important to further discuss inquiry paradigms that are concerned with a given set of assumptions. Interpretivism is based on the idea that we as individuals construct our own social reality through the mind and that only we individually are able to experience the world through personal perceptions, which are manifested through our preconceptions and beliefs (Nudzor, 2009: 125). In moving forward, these were the key methodological concepts of the study.

\section{Research Proposal}

Having successfully been offered the position to carry out the research, the idea that drove the research forward stemmed from two paragraphs of writing that I still held onto. For example:

Fig. 1

It has been said that 'a family that eats together stays together' and yet the importance of food within a school community is currently under-researched in 
the UK. The Peartree Academy provides a unique study and research opportunity into the impact of food upon learning and social behaviour. Previous research conducted at Cornell University (Jyoti, et al, 2005) has considered how food insecurity can affect academic performance and impair reading and mathematics development in pupils and there are also studies linked to the World Food Programme for example in Uganda (Adelman et al, 2008). However, such research does not consider the broader, and potentially more far reaching, impact of establishing a food-based ethos at the centre of school life. There are also very few schools in the UK who recognise the central role that food can play in terms of developing a community despite much publicity around the importance of good nutrition and adequate and healthy school meals promoted by advocates such as chef Jamie Oliver.

This research studentship will focus on a number of aspects related to the impact of food upon learning. For example, it could explore the social and life skills which students develop through meeting, making choices, eating and talking together in a welcoming restaurant environment rather than a traditional school canteen. It could consider the impact of challenging community perceptions of school in a context where learning and eating together are not high priorities in every home. The ways in which food can provide a meeting place for professional learning discussions and have an impact on students' attitudes to learning could also be studied.

In terms of developing the research proposal, these were the key ideas that drove the research forward. Through my interest in school food and learning, it was apparent that I would be required to explore a vast amount of literature in order to gain a multidisciplinary knowledge base on school meals. From this, I was able to establish a research proposal.

\section{Research Questions}

It is important to recognise the importance of re-drafting research questions. This will allow a prospective student embarking upon research to keep this in mind. It is a psychological struggle, which not only strengthens an early career researcher's mindset, but it crystallizes 
the key ideas that emerge from the research topic in question. On the $21^{\text {st }}$ August 2012, these were the research questions that had been developed through reviewing literature:

1. Does food have an impact on social skills development in and around the school restaurant?

2. Does the food culture at the school have an impact on learning in the English curriculum?

3. Do pupils, parents and staff use the school restaurant as a central hub for the community?

After numerous conversations with my supervisor and reflections, it was deemed unrealistic to try establishing a link between English as a subject and the impact food had on education attainment.

\section{Research Design}

The research design was written over a span of two years (from September 2012 until July 2014). At this point, I was able to establish clarity in terms of the specific details that made up this section in my thesis. Following numerous amendments, I was able to come up with the following research and subsidiary questions:

Main research question: What is the impact of the food environment upon learning?

Subsidiary research questions:

1. To what extent have food environments challenged learning in schools?

2. Do children's eating habits affect their attitudes towards learning in school?

3. How do eating behaviours impact on social skills development in schools?

4. How do teachers promote social skills and learning opportunities within a food environment?

I made the decision to adopt traditional qualitative research methods, which included both structured and unstructured observations, interviews and documentary evidence to collect my data. The data collection consisted of 80 hours of structured observations and 54 semi-structured interviews which took place in the school restaurant and around the learning spaces in the school, as well as the main staff rooms. The data collection took place during the period October 2013 to June 2014. 


\section{$\underline{\text { Observation }}$}

As an inexperienced ethnographer, there were some difficulties in preparing for observational research, which is closely related to the works of Delamont (as cited in Walford, 2008). Delamont (as cited in Walford, 2008) identified five things ethnographers found to be bewildering and problematic; how to observe, what to observe, what to write down, where to record observations, and what to do with the field notes and other writings afterwards (Delamont as cited in Walford, 2008: 39). Having spent some time in the school, the observation period was officially taking place. I would take mental notes and later record these onto a notepad, which were unstructured notes. Before conducting the more structured observations, I was unsure of how to observe and record the data, aside from using commonsense methods, which told me to position myself within the surroundings, which I decided was in the school restaurant.

\section{Research Practicalities}

There were a number of challenges that I faced as a researcher and the one that I would like to reflect on is observation. Gathering observational data proved difficult due to both inexperience and also a lack of preparation. Having read up on key texts surrounding observation (Walford, 2009; Walford, 2009), it quickly became apparent that a structured approach was required in order to record observations. Firstly, I made notes whilst visiting the school restaurant (See Fig. 2), although following a meeting with my supervisor, I decided to structure observations in a way which involved looking at certain situations and reporting on them using a chart (See Fig. 3).

Fig. 2

Day 2

Wednesday 2nd October 2013

Field Notes

Breakfast

8.20am 
As the winter weather kicks in, I am seeing a lot more winter clothing as pupils walk into the school for breakfast. It is a really welcoming environment, a key feature of the school which cannot go unnoticed.

\subsection{0am}

I can see a group of parents sat around some tables, chatting away. I was also offered to go into the staff room by the administrative staff I see on a regular basis (again, very welcoming). There are 2 local members of the community, who are also sitting around the table having a cup of coffee, whilst listening to music on their phones. Actually, I've noticed a number of parents and community members sitting in the restaurant, even grandparents

\section{$8.45 \mathrm{am}$}

Pupils begin making their way straight to class as they walk in through the reception and restaurant into the main corridor, others sit around finishing their breakfast.

\subsection{3am}

Having looked over some of Ted Wragg's work, I decided to quantify the qualitative. Therefore, I'll be numbering sentences in order to narrow down interpretations. Furthermore use the idea and techniques by Wragg (1993) to systematically develop a jigsaw puzzle with relevant ideas to draw from.

E.g.

Teacher as role model

Pupil taking role of adult

The animated teacher

\section{The Pilot Research in Practice}

The pilot data collection process began in November 2012, following a discussion in a tutorial with my supervisor, who suggested that this would be a useful way of scoping out the school and more importantly, the research methods employed. This process involved conducting interviews and observations for two days a week, for a one month period. It is said that all research designs need to be piloted or pre-tested and are often undermined by the new researcher (Gorard, 2001). Upon reflection, I would have spent additional time conducting the pilot study in order to gain further expertise, although I had already used interviews and collected documentary evidence for my undergraduate and postgraduate studies, the only exposure to observations I had gained, came through my time as becoming a 
qualified teacher. However, I did not spend time observing certain situations outside of the classroom environment and for that reason, initially, I felt lost and isolated.

A good pilot study involves selecting a sample in the same way as intended in the final study and negotiating access in the same way (Gorard, 2001). Although I felt confident conducting interviews, I felt less in control with observations and initially took an unstructured approach in recording a set of field notes, instead of later learning that picking out key situations, would better compliment my research study. For Gorard (2001), a pilot study should be seen as a full 'dress rehearsal' for the whole research design (Gorard, 2001: 102). I used an electronic recorder to capture the six interviews I carried out and transcribed three, in order to find out which way would best suit me. Following a hunt for the best piece of software, I ended up listening to the recording on the electronic recorder, whilst tapping the stop/start button and tapped away at the keyboard. I was able to learn a great deal from what the respondents had said by transcribing my own interviews. More importantly, transcribing data from interviews should be done by the primary researcher in order to gain the richness from the data. Although producing transcripts of interviews can bring a sense of richness to the overall analysis of the data, it is also important to recognise the views of the respondent, who may not feel comfortable being recorded. Having recorded every single interview and transcribed each one fully, my data set became valid and representative. 'Cherry-picking' the best sections to transcribe can come across as an attractive approach, although a researcher would then run the risk of ignoring data which appears boring, but may be crucial, particularly when certain correlations begin to surface (McGrath and Coles, 138).

\section{The Final Chapters Reworked, Revised, Restructured, Re- invented and Refined!}

By far, the most rewarding, challenging, thought provoking and complicated process was the write-up of those three 'key' chapters (Chapters 6, 7 and 8). As a researcher, this is an opportunity, to bring about a level of fluidity. My supervisor stated that the cleverness of the ideas presented emerge through the simplicity and clarity. The crystallization process is instrumental in providing clarity and honing in on those key ideas which were originally set 
out. These need to be developed and showcased. A rigorous methodology is likely to pave the way for a concise argument to be developed.

It is perhaps worth considering the variety of approaches available in carrying out ethnographic analysis. Hammersley and Atkinson (2007) and Mills and Morton (2013) draw on previous ethnographic portraits in order to illustrate ways of capturing the social world through description and it is the school setting that is particularly relevant here. Whilst it may appear daunting carrying out ethnographic research in the sporadic nature in which it exists, it is important to question the way findings are analyzed and presented (Atkinson et al, 2007). Looking for something during research can be a pitfall for ethnographic research in particular. It is about finding that truth without necessarily having to be representative (Mills and Morton, 2013).

\section{So What Was found?}

Methodologically, it was about establishing a framework that would be robust. Therefore, before being able to make any claims in terms of research outcomes, it was important to prioritise the methodology chapter and process up to this point. It was only upon taking a step back from my position as a researcher that I was able to build a clear argument for this research. It is therefore important to keep in mind that research needs to be critical and not only that, it needs to add purpose and value to the research area in question; one which ideally needs to add new literature.

In order to help understand what was found, it is important to establish the expectations of the lay audience. There are certain connotations attached to school meals which include the nutritional elements for one. The other one is usually the connection between food and learning. It has been difficult to deflect these questions into thoughts that are relevant to the individual who ask the question. It was only after attending and presenting at conferences and speaking to colleagues that I was able to establish a sound set of answers for certain questions. Overall, it was the critical aspect of power relationships that were explored in the school dining hall. More specifically, the power relationships between staff, pupils and parents. It was about recognizing how food played a role in bringing everyone together regardless of background. Social skills were at the forefront in terms of the main focus, but it was difficult to establish a link as dinner supervisors seemed to have a better idea 
of what it meant to practice social skills compared to the academic staff, who seemed to have social skills confused with basic skills. However, there is certainly room to explore these issues in further detail and ultimately, the aim of the findings chapters in the thesis are to develop a suitable critique.

\section{Lessons Learned from Ethnography at Peartree Academy}

What were the key pitfalls in ethnographic educational research? Methodologically, there were difficulties in deciding on the number of interview questions that were sufficient (Kvale, 1996). There were difficulties in eliminating the continuous prose of unstructured observations, which became field notes and although they were very useful, the structured observation enabled me to better structure the key arguments. This approach helped me to attach certain symbols and develop the three key thematic chapters.

One ethical issue emerged following an unexpected rendezvous with the Principal, in the middle of the school restaurant. From my interpretation, she was doing her very best to promote the school to me as the researcher, who would then go onto publishing this study. This had a detrimental bearing on my overall output and it was important to take a step back and be prepared for any criticism from the school. Following a reflective tutorial with my supervisor, I was able to disclose this situation and gain the necessary guidance from my supervisor, who pointed to the importance of prioritising ethical guidelines (BERA, 2011).

\section{Conclusion}

This case study has pondered a number of research discussions and the aim was to offer a holistic view taking a reflective approach whilst outlining key concepts and considering some difficulties, particularly with observational research. As set out in the abstract, this research involved exploring the impact of school food on learning. However, the key focus was to address research methodology and for that reason, there is little discussion on school food and learning. Overall, the data presented throughout this case study reveals the importance of reflection in ethnographic research and also highlights the complexities involved in gathering data. The exercise and discussion questions are geared towards thinking critically in terms of 
educational ethnographic research. Therefore, it is important to use this as a resource throughout research activity and reflections take time to digest. The overall narrative being presented in this case study is that ethnographic research is reflective in that it takes trial and error in order to overcome barriers and also try and gain a rich data set.

\section{Exercises and Discussion Questions}

1. What are the advantages and disadvantages of investigating school meals using interviews?

2. How is it possible to overcome difficulties in conducting observations in educational ethnographic research? Discuss using key texts from the reference list.

3. List two key pieces of advice offered by the author. Discuss how this advice could support your own research

4. What ethical triggers could potentially emerge from this research?

5. List some implications from conducting the pilot study. Discuss how this could support your own research

6. What is the importance of research questions and is it important to prioritise them?

7. How is a pilot study defined in this view?

8. What are the practical issues in exploring research on school meals?

9. Are you able to establish whether this researcher is an 'insider' or 'outsider'? Discuss.

\section{Further Readings}

Maidson, D. S. (2011) Critical Ethnography: Method, Ethics and Performance, London: Sage Publications

Ten Have, P. (2004) Understanding Qualitative Research and Ethnomethodology, London: Sage Publications

Whitehead, L. (2004) 'What is ethnography? Methodological, ontological and epistemological attributes', Cultural Ecology of health change, CEHC, Maryland: University of Maryland 
Wolcott, H. F. (1999) Ethnography: A way of seeing, London: Sage Publications

Woods, P. (1996) Researching the art of teaching: Ethnography for educational use, London: Routledge

\section{References}

Acker, S. (1999). Realities of Teachers' Work: Never a Dull Moment. London: Continuum

Adelman, S., Alderman, H. Gilligan, D. O., Lehrer, K. (2008) 'The Impact of Alternative Food for Education programs on school participation and education attainment in Northern Uganda', International Food Policy Research Institute, Washington DC

Atkinson, P. Coffey, A. Delamont, S., Lofland, J., Lofland, L. H. (2007) Handbook of Ethnography, London: Sage Publications

Ball, S. J. (1981) Beachside Comprehensive: A case-study of secondary schooling, Cambridge: Cambridge University Press

BERA (2011) 'Ethical Guidelines for Educational Research', British Educational Research Association [online] Available at:

http://content.yudu.com/Library/A2xnp5/Bera/resources/index.htm?referrerUrl=http://free.yudu. com/item/details/2023387/Bera (Accessed 30 October 2015)

Burgess, R. (1983) A study of Bishop McGregor School-Experiencing Comprehensive Education, London: Methuen \& Co. Ltd

Gorard, S. (2001) Quantitative Methods in Educational Research: The Role of Numbers Made Easy, London: Continuum

Hammersley, M. and Atkinson, P. (2007) Ethnography: Principles in Practice, London: Routledge

Jyoti, D. F., Frongillo, E. A., Jones, S. J. (2005) Food Insecurity Affects School Children's Academic Performance, Weight Gain and Social Skills, American Society for Nutrition, pp. $2831-2839$ 
Kvale, S. (1996) Interviews: An Introduction to Qualitative Research Interviewing, London: Sage Publications

McGrath, J. and Coles, A. (2013) Your Education Research Project Companion, London: Routledge

Mills, D. and Morton, M. (2013) Ethnography in Education, London: Sage Publications

Nudzor, H. P. (2009) 'A critical commentary on combined methods approach to researching educational and social issues', Issues in Educational Research, 19 (2), pp. 114 - 127

Pike, J. (2010) An ethnographic study of lunchtime experiences in primary school dining rooms, $\mathrm{PhD}$, University of Hull

Vygotsky, L. (1978) Mind in Society: The development of Higher Psychological Processes, Harvard: Harvard University Press

Walford, G. (2009) ‘Ethnography for Education', Ethnography and Education, 4 (3), pp. 271-282, Routledge, Taylor and Francis Group

Walford, G. (ed.) (2008) How to do educational ethnography, London: Tufnell Press 


\section{List of Figures}

Fig. 3

\begin{tabular}{|c|c|c|c|c|}
\hline $\begin{array}{l}\text { Period/ } \\
\text { Situation }\end{array}$ & $\begin{array}{l}\text { Who } \\
\text { (Year group) }\end{array}$ & What I have observed & What I heard & Further thoughts \\
\hline Break time & Year $7 / 8$ & $\begin{array}{l}10.13 a m \\
\text { As the bell rings, pupils } \\
\text { begin making their way } \\
\text { towards the next lessons. }\end{array}$ & $\begin{array}{l}\text { Staff member } \\
\text { "Ok, guys, let's } \\
\text { go!!!!!” }\end{array}$ & $\begin{array}{l}\text { As the school bell sounds, there is an immediate reaction } \\
\text { by pupils. }\end{array}$ \\
\hline Break time & Year 8 & \begin{tabular}{|l|} 
10.16am \\
A pupil approaches me
\end{tabular} & See Fig. 4 & Feeling like more of an insider. \\
\hline Post break & Year 9 & $\begin{array}{l}\text { A teacher sits and talks to } \\
\text { a pupil with a laptop, } \\
\text { discussing strategies of } \\
\text { some kind. }\end{array}$ & Muffled voices & $\begin{array}{l}\text { A regular occurrence. Although I did not record it } \\
\text { previously, I have noticed that there is usually a staff }\end{array}$ \\
\hline Post break & Principal & $\begin{array}{lcr}\text { Participating } & \text { with } \\
\text { conversation } \\
\text { principal }\end{array}$ & See Fig. 5 & $\begin{array}{l}\text { Having had another chance to speak with the Principal, it } \\
\text { reminded me of the importance of the interviews. I feel I } \\
\text { will be able to gain a valuable insight, which may be } \\
\text { slightly slanted in her view as she aims to act as a school } \\
\text { champion. I find myself enthused by her comments as I } \\
\text { engage with her views, stories and general comments. } \\
\text { Having spent some time observing in the school, I have } \\
\text { come to learn a great deal of how the school restaurant is } \\
\text { involved throughout the school day. }\end{array}$ \\
\hline
\end{tabular}

